\title{
EFFECT OF CUCUMIS MELO VAR. FLEXUOSUS LEAVES EXTRACT ON RENAL OXIDATIVE INJURY AND INFLAMMATION IN DIABETIC MALE ALBINO RATS
}

\author{
Marwa A. E. Abd El-Maksoud* \\ Zoology Department, Faculty of Science, Benha University, Qalyubia, Egypt
}

\begin{abstract}
Article History:
Received: 25 March 2019

Revised: 21 April 2019

Accepted: 24 April 2019

Published Online:

1 May 2019

Keywords:

Caspase-3

Faqqous leaves extract

Inflammation

Renal oxidative injury

STZ-diabetic rats

*Correspondence:

Marwa Abd El-Maksoud

Zoology Department, Faculty

of Science, Benha University

Qalyubia, Egypt

E-mail:

marwa.abdelmaksoud@fsc. bu.edu.eg
\end{abstract}

\begin{abstract}
Kidney disorders are common complications of uncontrolled diabetes. The present study aimed to evaluate the effect of oral administration of Cucumis melo var. flexuosus (snake melon or faqqous) leaves extract in three different doses (30, 60 and $120 \mathrm{mg} / \mathrm{kg}$ body weight) for 30 consecutive days on renal damage and inflammation in streptozotocin (STZ)-induced diabetic male albino rats (single intraperitoneal injection of $60 \mathrm{mg} \mathrm{STZ} / \mathrm{kg}$ body weight). The results showed that the snake melon leaves extract induced a significant decrease in the plasma level of the kidney injury molecule-1 (KIM-1) in the diabetic rats. In addition, the snake melon leaves extract caused a significant decrease in the levels of the renal thiobarbituric acid reactive substances (TBARS), tumor necrosis factor alpha (TNF- $\alpha$ ), interleukin (IL)-6, and caspase-3 of the diabetic rats. On the other hand, renal catalase (CAT) and superoxide dismutase (SOD) activities, as well as renal vascular endothelial growth factor (VEGF) level, were elevated significantly in the diabetic rats treated only with $60 \mathrm{mg}$ or $120 \mathrm{mg}$ of the snake melon leaves extract/kg body weight (compared with the diabetic control rats). In conclusion, the results of the present study revealed that the snake melon leaves extracts have a potential and effective role in inhibiting inflammation and oxidative stress in the kidney of diabetic rats.
\end{abstract}

\section{INTRODUCTION}

Diabetes mellitus, a metabolic disorder characterized by hyperglycemia with many other complications including microvascular and macrovascular complications, is one of the main causes of renal disorders ${ }^{[1,2]}$. Oxidative stress, due to the overproduction of reactive oxygen species (ROS), in diabetic subjects is greatly involved in the pathogenesis of renal damage and dysfunction $^{[3,4]}$. Excessive production of free radicals in diabetic rats caused renal damage through enhancing cellular lipid peroxidation, necrosis, and apoptosis ${ }^{[5]}$. The traditional medicinal herbs act as exogenous antioxidants, which make a balance between oxidation and antioxidation in biological systems through inhibiting the propagation of oxidative chain reactions and serving as free radical and singlet oxygen scavengers at the cellular level ${ }^{[6]}$. Cucumis melo, subsp. melo var. flexuosus (L.), 
(family Cucurbitaceae) or snake melon (faqqous) is an ancient crop in many parts of the world. It used as a raw vegetable for salad, and in medicine as one of the natural antioxidants ${ }^{[7]}$. It has many bioactive phytochemicals like alkaloids, flavonoids, tannins, and phenolic compounds that are responsible for its antioxidant property ${ }^{[7,8]}$. Previously, the antihyperglycemic, insulin secretagogue, and neuroprotective activities of the snake melon leaves extract in streptozotocin (STZ)-diabetic rats were reported by our laboratory ${ }^{[8,9]}$. The present study aimed to extend our laboratory findings by further exploring other beneficial effects of the snake melon through evaluating the renoprotective activity of three different doses of its leaves extract in STZ-induced diabetic male albino rats, with especial reference to the renal oxidative injury and inflammation.

\section{MATERIAL AND METHODS Extract}

Snake melon leaves extract were collected from different healthy agricultural fields in Benha (Qalyubia, Egypt) and authenticated by our colleagues in the Faculty of Agriculture, Benha University. The fresh leaves were dried in dark area at room temperature, crushed to fine powder and extracted with ethanol using a Soxhlet apparatus as previously described ${ }^{[8]}$. The extract was evaporated to dryness and stored at $4^{\circ} \mathrm{C}$.

\section{Experimental induction of diabetes}

In the present study, diabetes was induced in experimental animals by a single intraperitoneal injection of $60 \mathrm{mg} / \mathrm{kg}$ body weight (b.wt) of freshly prepared solution of STZ (Sigma Co., St. Louis, MO, USA) dissolved in $0.1 \mathrm{M}$ citrate buffer $(\mathrm{pH} 4.5)$ according to El-Shafey et $a ._{.}^{[10]}$. Rats were given $5 \%$ glucose solution in drinking water for two days to avoid hyperglycemic coma. Rats were examined for blood glucose levels 48 hours after STZ injection. Blood samples from the lateral tail vein of overnight fasted rats were withdrawn to measure glucose concentration, and rats with glucose concentration $\geq 200 \mathrm{mg} / \mathrm{dL}$ were selected for the study.

\section{Experimental design}

Male Wistar albino rats (Rattus norvegicus), weighing $160 \pm 10 \mathrm{~g}$, were obtained from the Helwan Farm of Egyptian Organization for Vaccine and Biological Preparations. They were maintained under standard laboratory conditions $\left(25 \pm 2{ }^{\circ} \mathrm{C}, 12\right.$ hours light/dark cycle and given food and water ad libitum) for ten days before the onset of the experiment. Rats were humanely treated according to the ethical guidelines of the Faculty of Science, Benha University. They were randomly divided into five groups "seven rats each" as follows: (a) group I (non-diabetic control rats) that received vehicle (water) orally (by gavage) for 30 consecutive days, (b) group II (diabetic control rats) that injected intraperitoneally with a single dose of STZ $(60 \mathrm{mg} / \mathrm{kg}$ b.wt) and housed under the same experimental conditions for 30 days, (c) groups III, IV, and V, STZ-diabetic rats that treated orally with 30,60 or $120 \mathrm{mg} / \mathrm{kg}$ b.wt of snake melon leaves extract, respectively, dissolved in $1.0 \mathrm{~mL}$ distilled water for 30 consecutive days after inducing diabetes.

\section{Sample preparations}

At the end of the experiment, the overnight fasting animals were anaesthetized by light inhalation of diethyl ether; blood samples were drawn from the postcaval vein and directly transported to tubes containing ethylenediamine tetra-acetic acid (EDTA). Blood samples were centrifuged at $1500 \times g$ for $15 \mathrm{~min}$; then plasma was separated and frozen at $-20^{\circ} \mathrm{C}$ until used for kidney injury molecule-1 (KIM-1) analysis. The KIM-1 level was determined by a sandwich ELISA rat kit purchased from the Cloud-Clone Corporation (Katy, TX, USA). Immediately, kidneys were dissected out of the rats, washed, and homogenized in ice-cold phosphate buffer saline (PBS, pH 7.2). The homogenate was centrifuged at $5000 \times g$ for $5 \mathrm{~min}$. The supernatants were stored at $-20^{\circ} \mathrm{C}$ until used for the biochemical assays. 
Biochemical assays in the kidney

The level of renal thiobarbituric acid reactive substances (TBARS) and the activities of catalase (CAT) and superoxide dismutase (SOD) were determined by colorimetric methods using kits purchased from BioVision (Milpitas, CA, USA). The concentrations of renal tumor necrosis factor (TNF- $\alpha$ ), interleukin (IL)-6, vascular endothelial growth factor (VEGF), and caspase-3 were measured by ELISA rat kit purchased from the Cloud-Clone Corporation.

\section{Statistical analysis}

Results are presented as means \pm standard deviations of seven readings. Statistical analyses of the results were performed by the one-way analysis of variance (ANOVA), followed by Duncan's multiple range test ${ }^{[11]}$. The significance level was set at $P<0.05$ by using the Statistical Package for Social Science (SPSS) computer program (version 20.00) produced by IBM Software, Inc. Chicago, USA.

\section{RESULTS}

Effect of snake melon leaves extract on plasma KIM-1 level in STZ-diabetic rats

Figure "1" showed that the plasma KIM-1 level increased significantly $(P<0.05)$ in all diabetic groups compared with the nondiabetic group. On the other hand, the diabetic rats treated with snake melon leaves extract showed a significant decrease in the plasma KIM-1 level in a dose dependentmanner compared with the diabetic control rats.

Effect of snake melon leaves extract on renal oxidative stress parameters in STZdiabetic rats

In the diabetic control rats, there was a significant increase $(P<0.05)$ in the renal TBARS level compared with all other groups (Table 1). The high dose of snake melon leaves extract $(120 \mathrm{mg} / \mathrm{kg} \quad$ b.wt $)$ reduced the renal TBARS level of the diabetic rats more than the low and mild doses (30 and $60 \mathrm{mg} / \mathrm{kg}$ b.wt, respectively).
On the other hand, renal CAT and SOD activities reduced significantly $(P<0.05)$ in the diabetic control rats compared with the non-diabetic rats. While, the diabetic rats treated with snake melon leaves extract showed a significant increase in CAT and SOD activities, especially at the high doses (Table 1).

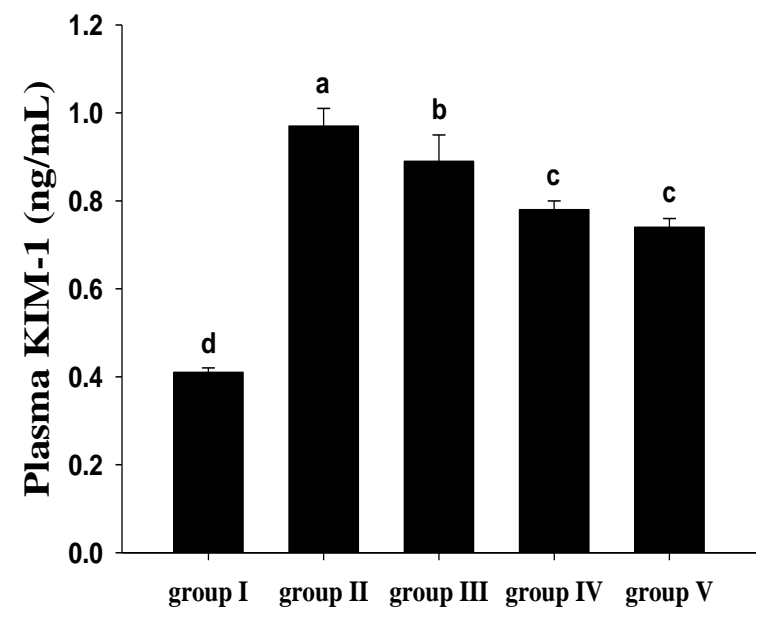

Figure 1: Effect of snake melon leaves extract on plasma kidney injury molecule (KIM)-1 level in streptozotocin (STZ)diabetic rats. Data are presented as means \pm standard deviations $(\mathrm{n}=7)$. Group I: nondiabetic control rats, group II: STZ-diabetic rats, groups III, IV, and V: STZ-diabetic rats received 30,60 or $120 \mathrm{mg} / \mathrm{kg}$ body weight of snake melon leaves extract, respectively. Values with different letters in the figure were significantly different $(P<0.05)$.

Effect of snake melon leaves extract on renal proinflammatory cytokines in STZdiabetic rats

The levels of proinflammatory cytokines (TNF- $\alpha$ and IL-6) elevated significantly $(P<0.05)$ in the renal tissues of diabetic control rats compared with the non-diabetic rats and the snake melon leaves extract treated diabetic rats (Table 2). While, the snake melon leaves extract induced a significant reduction in the renal proinflammatory cytokines levels of the diabetic rats. 
Table 1: Effect of snake melon leaves extract on renal lipid peroxidation level and the activity of enzymic antioxidants in streptozotocin (STZ)-diabetic rats.

\begin{tabular}{cccccc}
\hline & Group I & Group II & Group III & Group IV & Group V \\
\cline { 2 - 5 } TBARS & $12.25 \pm 1.96^{\mathrm{d}}$ & $25.37 \pm 1.79^{\mathrm{a}}$ & $22.31 \pm 0.83^{\mathrm{b}}$ & $20.12 \pm 0.53^{\mathrm{b}}$ & $17.53 \pm 0.69^{\mathrm{c}}$ \\
$(\mu \mathrm{mol} / 100 \mathrm{mg}$ tissue $)$ & & & & & \\
CAT & $1.33 \pm 0.10^{\mathrm{a}}$ & $0.62 \pm 0.04^{\mathrm{d}}$ & $0.67 \pm 0.10^{\mathrm{cd}}$ & $0.80 \pm 0.07^{\mathrm{bc}}$ & $0.88 \pm 0.06^{\mathrm{b}}$ \\
$(\mu \mathrm{mol} / 100 \mathrm{mg}$ tissue $)$ & & & & \\
SOD & & & & & \\
$(\mathrm{U} / 100 \mathrm{mg}$ tissue $)$ & $13.30 \pm 0.54^{\mathrm{a}}$ & $8.47 \pm 0.50^{\mathrm{d}}$ & $8.77 \pm 0.39^{\mathrm{cd}}$ & $9.57 \pm 0.41^{\mathrm{bc}}$ & $10.19 \pm 0.61^{\mathrm{a}}$ \\
\hline
\end{tabular}

Data are presented as means \pm standard deviations $(\mathrm{n}=7)$. Group I: non-diabetic control rats, group II: STZ-diabetic rats, groups III, IV, and V: STZ-diabetic rats received 30, 60 or $120 \mathrm{mg} / \mathrm{kg}$ body weight of snake melon leaves extract, respectively. TBARS: thiobarbituric acid reactive substances, CAT: catalase, SOD: superoxide dismutase. Values with different letters in the same row were significantly different $(P<0.05)$.

Table 2: Effect of snake melon leaves extract on renal proinflammatory cytokines (TNF- $\alpha$ and IL-6), VEGF, and caspase-3 levels in streptozotocin (STZ)-diabetic rats.

\begin{tabular}{|c|c|c|c|c|c|}
\hline & Group I & Group II & Group III & Group IV & Group V \\
\hline $\begin{array}{c}\text { TNF- } \alpha \\
\text { (pg/100 mg tissue) }\end{array}$ & $172.8 \pm 10.5^{\mathrm{e}}$ & $338.2 \pm 15.1^{\mathrm{a}}$ & $305.7 \pm 5.8^{\mathrm{b}}$ & $282.4 \pm 10.4^{\mathrm{c}}$ & $256.7 \pm 9.9^{\mathrm{d}}$ \\
\hline $\begin{array}{c}\text { IL-6 } \\
\text { (pg/100 mg tissue) }\end{array}$ & $171.6 \pm 11.1^{\mathrm{c}}$ & $354.3 \pm 43.4^{\mathrm{a}}$ & $283.6 \pm 21.7^{\mathrm{b}}$ & $264.1 \pm 12.0^{\mathrm{b}}$ & $243.0 \pm 8.4^{\mathrm{b}}$ \\
\hline $\begin{array}{c}\text { VEGF } \\
\text { (pg/100 mg tissue) }\end{array}$ & $369.3 \pm 37.0^{\mathrm{a}}$ & $224.2 \pm 27.2^{\mathrm{d}}$ & $260.4 \pm 8.5^{\mathrm{cd}}$ & $283.8 \pm 9.3^{\mathrm{bc}}$ & $321.3 \pm 19.1^{b}$ \\
\hline $\begin{array}{c}\text { Caspase-3 } \\
\text { (ng/100 mg tissue) }\end{array}$ & $4.45 \pm 0.64^{\mathrm{d}}$ & $10.11 \pm 0.97^{\mathrm{a}}$ & $8.89 \pm 0.14^{\mathrm{b}}$ & $7.62 \pm 0.38^{\mathrm{c}}$ & $7.14 \pm 0.13^{\mathrm{c}}$ \\
\hline
\end{tabular}

Data are presented as means \pm standard deviations $(\mathrm{n}=7)$. Group I: non-diabetic control rats, group II: STZ-diabetic rats, groups III, IV, and V: STZ-diabetic rats received 30, 60 or $120 \mathrm{mg} / \mathrm{kg}$ body weight of snake melon leaves extract, respectively. TNF: tumor necrosis factor, IL: interleukin, VEGF: vascular endothelial growth factor. Values with different letters in the same row were significantly different $(P<0.05)$.

Effect of snake melon leaves extract on renal vascular endothelial growth factor and caspase-3 levels in STZ-diabetic rats Induction of diabetes in rats by STZ caused a significant decrease and increase $(P<0.05)$ in the renal VEGF and caspase-3 levels, respectively, compared with the non- diabetic rats (Table 2). On the other hand, the renal VEGF level increased significantly, but the caspase-3 level reduced significantly, in the diabetic rats by the snake melon leaves extract especially at the higher doses $(60$ and $120 \mathrm{mg} / \mathrm{kg}$ b.wt, respectively). 


\section{DISCUSSION}

Hyperglycemia enhanced ROS production in mesangial and tubular epithelial cells in diabetic rats, and hence increased the renal oxidative stress. It can also induce damage in the cells and micro-blood vessels of the kidney causing renal failure ${ }^{[4,12]}$. In addition, oxidative stress has an essential role in the pathogenesis of acute and chronic kidney diseases $^{[13,14]}$. Induction of diabetes was carried out in the present study by using STZ, which increased the oxidative stress and augmented the destruction of beta cells in the Langerhans islets that are responsible for insulin secretion ${ }^{[15]}$. The diabetic rats showed an elevation in the renal TBARS level and a reduction in the activities of renal enzymic antioxidant (CAT and SOD), probably due to the enhancement of free radical production by STZ. In addition, STZdiabetic rat showed an elevation in the plasma KIM level. KIM-1, a transmembrane protein expressed in the damaged regions of proximal renal tubular epithelial cells, is considered as a sensitive biomarker for kidney injury ${ }^{[16]}$. The elevation in the plasma KIM-1 level of the diabetic rats may also be attributed to the increment in the production of ROS and the reduction in the antioxidant defenses that induced by STZ ${ }^{[17]}$.

Many plant extracts and natural products of animal sources had both antioxidant and antidiabetic activities, which could protect kidneys from injury in diabetic subjects by improving the cellular antioxidant defense system and hence reducing the lipid peroxidation ${ }^{[1,18,19]}$. Our previous study concluded that snake melon leaves extract showed a blood glucose lowering activity and improved the plasma insulin level in STZ-diabetic rats ${ }^{[8]}$. In addition, the current study proved the renoprotective activity of snake melon leaves extract, which was able to decrease the plasma KIM-1 levels of diabetic rats, probably through its antioxidant effect. Indeed, snake melon leaves extract decreased the renal lipid peroxidation and improved the activities of CAT and SOD. Other research studies reported the free radical scavenging activity of snake melon, which mainly related to its phenolic compounds especially flavonoids ${ }^{[8,20]}$.

The renal proinflammatory cytokines considered as biomarkers in the diagnosis of diabetic renal inflammation and injury, especially if the renal antioxidant defense system was weak ${ }^{[21]}$. Excessive production of free radicals in the STZ-diabetic rats may activate many proinflammatory transcription factors and mediator leading to tissue inflammation and injury ${ }^{[22]}$. Indeed, an increase in the renal proinflammatory cytokines (TNF- $\alpha$ and IL-6) was detected in the current study in the STZ-diabetic rats. Renal TNF- $\alpha$ may enhance cellular apoptosis, cause a disruption of the glomerular permeability barrier, and act as an inflammatory cofactor of high glucose level ${ }^{[21,22]}$. On the other hand, snake melon extract reduced significantly the production of proinflammatory cytokines in renal tissues of STZ-diabetic rats, which likely resulted from its antioxidant and/or antiinflammatory activities. Also, Preeti and $\mathrm{Raju}^{[23]}$ revealed that snake melon seeds had many bioactive components that showed many biological activities including the antiinflammatory activity.

The VEGF, a protein secreted by podocytes of Bowman's capsule, is necessary for the survival of the endothelial cells, podocytes, and mesangial cells. Also, it is an essential regulator of angiogenesis and vascular permeability ${ }^{[24]}$. Apoptosis is a natural mechanism of cell death that is regulated by cysteine-dependent specific aspartate proteases or caspases; activation of caspase-3 leads to an increase in apoptotic index ${ }^{[21,25]}$. In the present study, STZ-diabetic rats showed a significant decrease and increase in the renal VEGF and caspase-3 levels, respectively. The reduction of VEGF expression was associated with podocyte loss and a defect in the glomerular filtration rate ${ }^{[26]}$. In the current study, snake melon leaves extract (especially at the higher doses, 60 and $120 \mathrm{mg} / \mathrm{kg}$ b.wt) showed a renoprotective activity and succeeded to protect the 
podocyte and decrease renal apoptosis in the diabetic rats by improving the renal VEGF level and decreasing the renal caspase-3, respectively.

In conclusion, the results of the present study revealed that the snake melon leaves extracts (especially at doses of 60 and $120 \mathrm{mg} / \mathrm{kg} \mathrm{b} . \mathrm{wt}$ ) inhibited the renal damage of STZ-diabetic rats through: (a) improving the enzymic antioxidant defense system of renal tissues, (b) enhancing the production of renal VEGF, (c) decreasing the production of renal proinflammatory cytokines, (d) suppressing the renal lipid peroxidation and apoptosis.

\section{ACKNOWLEDGMENTS}

This research received no specific grant from any funding agency in the public, commercial or not-for-profit sectors. The author reports no declarations of interest.

\section{REFERENCES}

[1] Katyal, T.; Sharma, M.; Sidhu, K. et al. (2009). Beneficial effects of antioxidants on oxidative stress and diabetes-induced experimental nephropathy. Pharmacol, 1: 252-263.

[2] Fernandes, S. M.; Cordeiro, P. M.; Watanabe, M. et al. (2016). The role of oxidative stress in streptozotocininduced diabetic nephropathy in rats. Arch Endocrinol Metab, 60: 443449.

[3] Wang, J.; Liu, H.; Li, N. et al. (2014). The protective effect of fucoidan in rats with streptozotocin-induced diabetic nephropathy. Mar Drugs, 12: 3292-3306.

[4] Nazar, C. M. J. (2014). Diabetic nephropathy; principles of diagnosis and treatment of diabetic kidney disease. J Nephropharmacol, 3: 15-20.

[5] Tavafi, M.; Ahmad, H.; Khalatbari, A. et al. (2011). Rosmarinic acid ameliorates diabetic nephropathy in uninephrectomized diabetic rats. Iran J Basic Med Sci, 14: 275-283.
[6] Xu, D. P.; Li, Y.; Meng, X. et al. (2017). Natural antioxidants in foods and medicinal plants: extraction, assessment and resources. Int $\mathrm{J}$ Mol Sci 18(1): 69 (DOI: 10.3390/ijms 18010096).

[7] Krishnamachari, H. and Nithyalakshmi, V. (2017). Phytochemical analysis and antioxidant potential of Cucumis melo seeds. Int $\mathrm{J}$ Life Sci Scienti Res, 3: 863-867.

[8] Ibrahim, D. S. and Abd El-Maksoud, M. A. E. (2018). Antioxidant and antidiabetic activities of Cucumis melo var. flexuosus leaf extract. Indian J Physiol Pharmacol, 62: 445452.

[9] Ibrahim, D. S. (2017). Neuroprotective effect of Cucumis melo var. flexuosus leaf extract on the brains of rats with streptozotocin-induced diabetes. Metab Brain Dis, 32: 69-75.

[10] El Shafey, A. A. M.; El-Ezabi, M. M.; Seliem, M. M. E. et al. (2013). Effect of Gymnema sylvestre $\mathrm{R}$. Br. leaf extract on certain physiological parameters of diabetic rats. J King Saud Univ Sci, 25: 135-141.

[11] Duncan, B. D. (1957). Multiple range tests for correlated and heteroscedastic means. Biometrics, 13: 359-364.

[12] Arora M. K. and Singh U. K. (2013). Molecular mechanisms in the pathogenesis of diabetic nephropathy: an update. Vascul Pharmacol, 58: 259271.

[13] Salmon, A. B.; Richardson, A. and Pérez, V. I. (2010). Update on the oxidative stress theory of aging: does oxidative stress play a role in aging or healthy aging? Free Radic Biol Med, 48: 642-655.

[14] Zhang, H. Q.; Fang, B. J.; Zhang, Q. Z. et al. (2016). Renoprotective effect of lidocaine on streptozotocin-induced diabetic nephropathy. Int J Clin Exp Med, 9: 14254-14259.

[15] Akbarzadeh, A.; Norouzian, D.; Mehrabi, M. R. et al. (2007). Induction 
of diabetes by streptozotocin in rats. Ind J Clin Biochem, 22: 60-64.

[16] Ahmed, S. A. and Hamed, M. A. (2015). Kidney injury molecule-1 as a predicting factor for inflamed kidney, diabetic and diabetic. J Diabetes Metab Disord, 14: 6 (DOI: 10.1186/s40200015-0131-8).

[17] Orhan, N.; Aslan, M.; Orhan, D. D. et al. (2006). In-vivo assessment of antidiabetic and antioxidant activities of grapevine leaves (Vitis vinifera) in diabetic rats. J Ethnopharmacol, 108: 280-286.

[18] Sameni, H. R.; Ramhormozi, P.; Bandegi, A. R. et al. (2016). Effects of ethanol extract of propolis on histopathological changes and anti-oxidant defense of kidney in a rat model for type 1 diabetes mellitus. J Diabetes Investig, 7: 506-513.

[19] Balasubramanian, T.; Senthilkumar, G. P.; Karthikeyan, M. et al. (2014). Therapeutic effect of stereospermum suavelolens on diabetic nephropathy. Clin Exp Pharmacol, 4(5): 162 (DOI: 10.4172/2161-1459.1000162).

[20] Widowati, W. (2015). Phytochemical, free radical scavenging and cytotoxic assay of Cucumis Melo L. extract and $\beta$-carotene. Journal of Advanced Agricultural Technologies, 2: 114-119.

[21] Wagener F. A. D. T. G.; Dekker D.; Berden J. H., et al. (2009). The role of reactive oxygen species in apoptosis of the diabetic kidney. Apoptosis, 14: 1451-1458.

[22] Saddiq, A. A. and Mohamed, A. M. M. (2019). Rescue of inflammatory renal damage by medicinal plant extracts in diabetic rats. Int $\mathbf{J}$ Life Sci Pharma Res, 9: 24-33.

[23] Preeti and Raju, P. N. (2107). Comprehensive overview of Cucumis melo. The Pharma Innovation Journal, 6(10): 181-186.

[24] Tufro A. and Veron D. (2012). VEGF and podocytes in diabetic nephropathy. Semin Nephrol, 32: 385393.

[25] Chandra J.; Zhivotovsky B.; Zaitsev S. et al. (2001). Role of apoptosis in pancreatic beta-cell death in diabetes. Diabetes, 50(Suppl 1): S44-47.

[26] Baelde, H. J.; Eikmans M. and Lappin D. W. P. (2007). Reduction of VEGF-A and CTGF expression in diabetic nephropathy is associated with podocyte loss. Kidney Int, 71: 637-645.

\section{How to cite this article:}

Abd El-Maksoud, M. A. E. (2019). Effect of Cucumis melo var. flexuosus leaves extract on renal oxidative injury and inflammation in diabetic male albino rats. Egyptian Journal of Zoology, 71: 13-20 (DOI: 10.12816/ejz.2019.10515.1007). 


\section{تأثير مستخلص أوراق نبات القثاء على الضرر الكُلوي التأكسدي والالتهاب

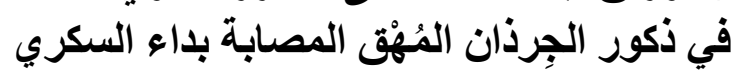

\section{مروة عاطف عليوة عبد المقصود}

قسم علم الحيوان، كلية العلوم، جامعة بنها، القليوبية، جمهورية مصر العربية

تُعتبر اعتلالات الكُلى من المضاعفات الثائعة لداء السكري غير الخاضع للسيطرة الدو ائية. ولذلك هدفت الدراسة الحالية

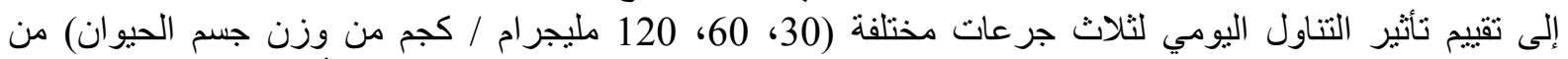

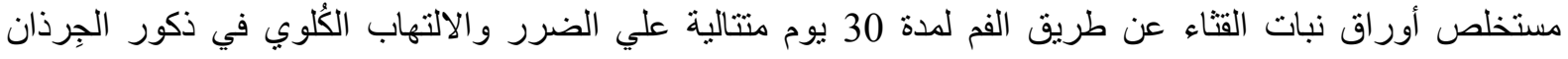

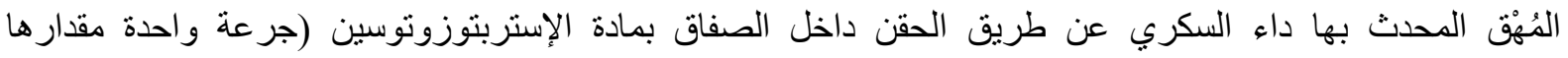

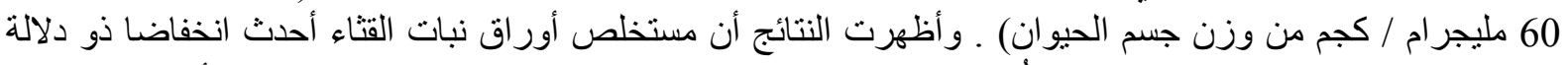

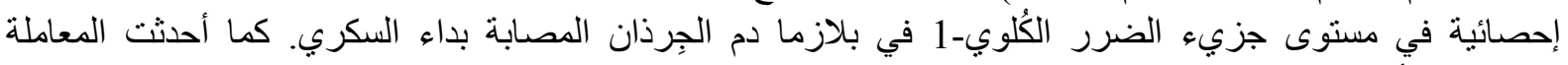

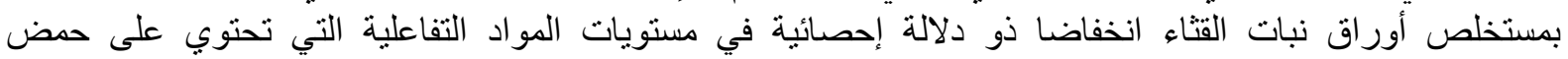

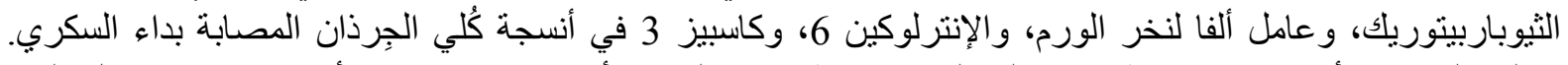

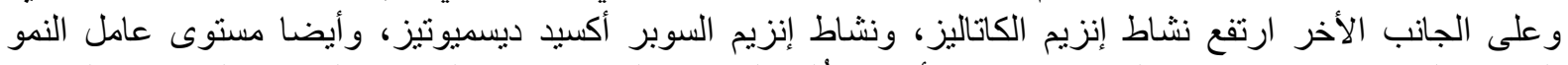

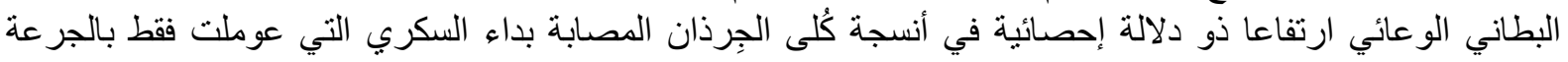

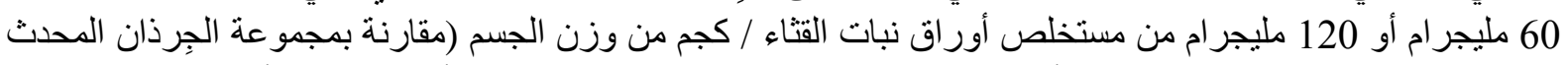

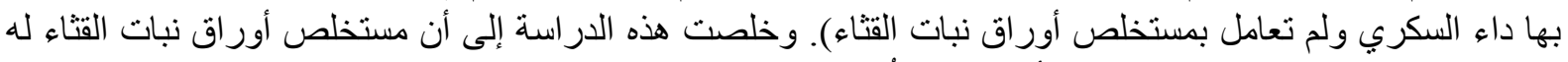

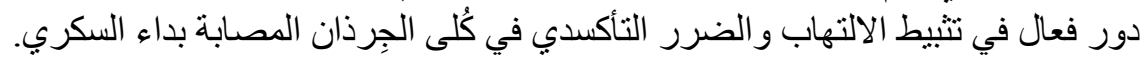

